\title{
TOWARDS A FRAMEWORK FOR THE DESIGN OF VARIETY- ORIENTED PRODUCT-SERVICE SYSTEMS
}

\author{
C. Rennpferdt ${ }^{凶}$ and D. Krause \\ Hamburg University of Technology, Germany \\ $₫$ christoph.rennpferdt@tuhh.de
}

\begin{abstract}
Due to increasing cost pressure, companies are expanding their product range and therefore increasingly offering so-called product-service systems (PSS) to increase sales. At the same time, PSS can also contribute to an increase in variety-induced complexity in the company, which ultimately further increases cost pressure. In this article, the causes and effects of variety-induced complexity through products, services and PSS are analysed and the need for a new PSS design method is then demonstrated. Finally, a new framework is presented that enables the design of variety-oriented PSS.
\end{abstract}

Keywords: product-service systems (PSS), design methods, modularisation, variety-induced complexity

\section{Introduction}

Due to megatrends such as globalization or individualization, manufacturing companies are exposed to high cost pressure. This leads to a decline in competitiveness (Krause and Gebhardt, 2018). As a way out, companies often try to generate higher demand by diversifying their product range (ElMaraghy et al., 2013; Krause et al., 2014). Further drivers of diversification are dynamic requirements and customers' individualisation wishes. In the long term, however, this strategy will lead to an increase in product and process variety within the company and, in particular, to an increase in variety-induced complexity. This leads to a reduction in profitability and ultimately increases cost pressure (Krause and Gebhardt, 2018). These relationships are referred to as the vicious circle of diversification (Krause and Gebhardt, 2018) and are illustrated in Figure 1.

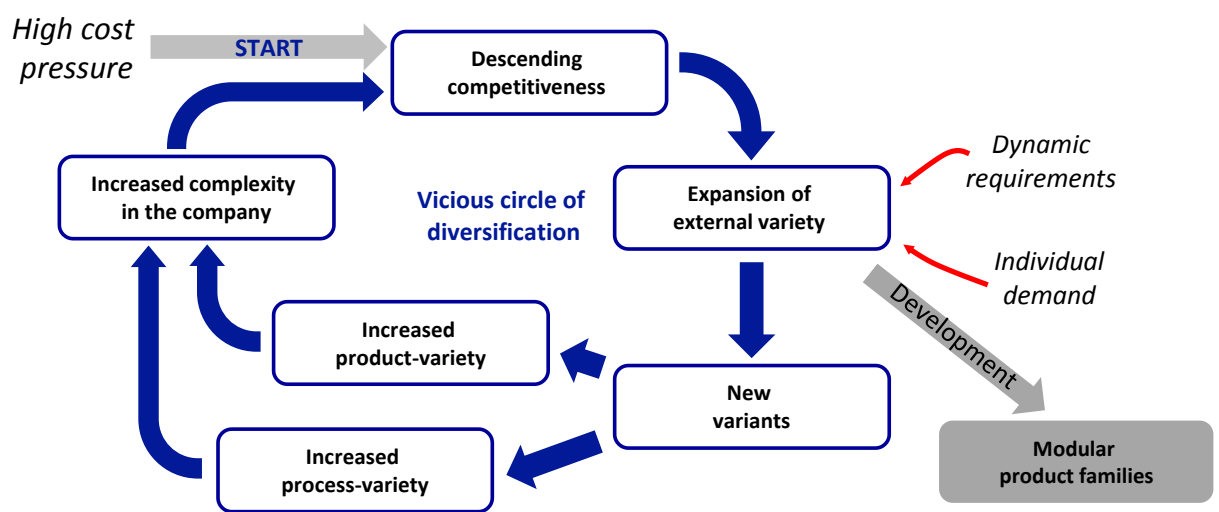

Figure 1. Vicious circle of diversification (Rathnow, 1993; Krause and Gebhardt, 2018) 
One possibility to avoid cost pressure is the transition from a manufacturing company to a solution provider (Alonso-Rasgado and Thompson, 2006). In this context, associated services are offered in addition to the product. The solutions consist of products and services and are referred to as productservice systems (PSS). The term servitization is used to describe the gradual relationship between products and services (Tukker, 2004; Kreye et al., 2015). PSS offer many advantages for suppliers and users, such as stronger customer loyalty, optimised recycling management or the creation of new sales opportunities by differentiating from competitors (Mont, 2002; Alonso-Rasgado and Thompson, 2006; Isaksson et al., 2009).

By offering PSS, the solution space for realizing customer requirements is expanded (Sundin et al., 2009) and the external diversity can be increased (Isaksson et al., 2009). The problem here is that the prior knowledge for structured service development is often lacking and ad-hoc solutions are implemented instead (Larsen et al., 2019). In the long term, however, the processes that are necessary to fulfil the services ensure that the process diversity increases and ultimately the complexity in the company only increases further (Ezzat et al., 2019).

One way of escaping the vicious circle in the long term, as shown in Figure 1, is the development of modular product families (Krause and Gebhardt, 2018). These make it possible to reduce the variety of components, the variety of processes and thus reducing the variety-induced complexity in the company. In order to meet the changed requirements of PSS development, existing methods for product development must be adapted in order to be able to explicitly consider process complexity within the PSS development.

Variety-induced complexity is a well-known topic in product development. In the context of PSS development, the importance of complexity is increasing, because in addition to product complexity, also service and process complexity arise and must be considered in an interdisciplinary manner. In this contribution, the relevance and effects of variety-induced complexity will be highlighted. Based on the findings, a framework for the development of variety-oriented PSS is presented.

In this contribution, section 2 explains the basics required for PSS, products and services. Section 3 then contains a literature review on the significance of variety and variety-induced complexity in product, service and PSS development and the derivation of the need for action. Based on this, an initial framework for the development of variety-oriented PSS is presented in section 4. In addition to the variety-oriented design of the product and service components, the focus of the framework is on systematic planning of variety through a systematic division of customer requirements into product and service specifications. Finally, section 5 summarises the contribution and gives an outlook on further steps.

\section{Background}

Product-service systems (PSS) have various designations in the literature (Cavalieri and Pezzotta, 2012), such as Total Care Product (Alonso-Rasgado and Thompson, 2006) or Industrial Product Service Systems (Meier et al., 2010). Despite different names, the definitions are all very similar. A widely used definition of PSS is the one of Goedkoop (1999): It defines PSS as a marketable set of products and services to meet customer needs. Other authors also describe PSS as an integrated set of products and services that offers customers additional value (Alonso-Rasgado and Thompson, 2006; Tukker and Tischner, 2006; Baines et al., 2007; Vasantha et al., 2012). The ratio between service and product is not fixed, but can vary between the two extremes pure product and pure service (Goedkoop, 1999; Tukker, 2004). A customer need can therefore be met by different compositions of product and service shares (Tukker, 2004). Different types of PSS are shown schematically in Figure 2. Product-oriented PSS focus on the sale of the product, whereas in use-oriented PSS, e.g. renting of machines, the business model is not only based on selling products. Instead, it is a value cocreation of product and services. In result-oriented PSS, like pay-per-use business models, customers do not buy machines anymore but pay for a defined outcome instead (Tukker, 2004).

According to Goedkoop (1999), a product is a tangible good that is manufactured for sale and serves to meet customer needs. Shostack (1982) describes products as tangible and existent in space and time. Tangible goods can be composed in different proportions of mechanical, electronic and software component. In this article, the term product is used to describe a tangible good that can be composed of mechanical, electronic and software components to meet customer needs. 


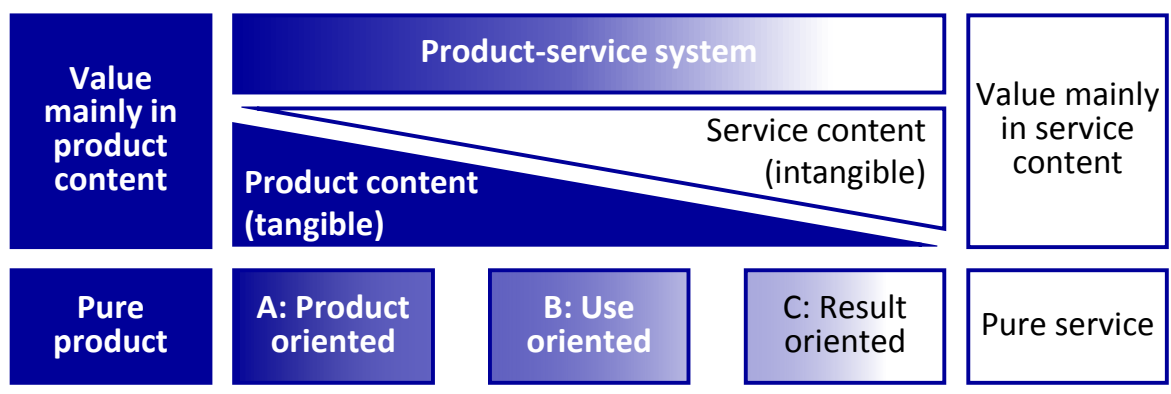

Figure 2. Different categories of product-service systems (according to Tukker, 2004)

In contrast to a product, a service is intangible. It is temporally determined (Shostack, 1982) and describes a change of state, from one object to another, with an economic value (Goedkoop, 1999; Hara et al., 2009). To distinguish services from products, Alonso-Rasgado and Thompson (2006) name five properties of services: intangibility, inseparability, perishability, ownership and heterogeneity. While physical products are tangible, services consist of processes and skills of people and other resources which achieve the desired output only together (Goldstein et al., 2002; AlonsoRasgado and Thompson, 2006). Because they are not tangible, services are produced and consumed simultaneously, they cannot be stored (Alonso-Rasgado and Thompson, 2006). Another essential feature of services offered in this context is complexity (Benedettini and Neely, 2012).

Complexity is not only a property of services, but can also be caused by products and PSS. The effects of complexity, and in particular the variety-induced complexity, are explained and analysed in the following section.

\section{Variety-induced complexity and PSS}

Complexity is an interdisciplinary topic and, according to Brosch and Krause (2011), can be viewed from the perspective of product development from four different perspectives. In the following, the focus is on the perspective of design property. This includes the number of elements and their relationships and the variability over time (Brosch and Krause, 2011). The expansion of the product range is usually realized by generating new variants, i.e. the variety is increased. In order to manage the increased number of variants, there are various approaches in the field of variety management. The goal of variant management is usually to reduce variety-induced complexity and the resulting complexity costs (ElMaraghy et al., 2013).

\subsection{Variety-induced complexity caused by products}

The state of the art is that an increasing external diversity in the company increases the variety of the products and thus has effects on the variety-induced complexity in the company (ElMaraghy et al., 2013). Ripperda and Krause (2017) have analysed and summarised the effects of a high variety in the different product life phases. For example, a high degree of variety in product development results in additional expenditure in the development of new products, in the documentation of the development or in additional testing (Ripperda and Krause, 2017). In the usage phase, a high product variety means a high spare parts inventory, but also a higher risk of complaints (Ripperda and Krause, 2017). Multidisciplinary is an additional driver of complexity, since products no longer consist only of mechanical components, but also electrical and software components (ElMaraghy et al., 2012). All this leads to an increasing complexity in the company and can be summarized as variety-induced complexity (Ripperda and Krause, 2017).

The development of modular product structures is proposed as a measure to reduce variety-induced complexity (ElMaraghy et al., 2013; Ripperda and Krause, 2017). An established approach aimed at reducing internal product and process variety is the Integrated PKT-Approach for developing modular product families developed by the Institute of Product Development and Mechanical Engineering Design (PKT) (Krause et al., 2014; Krause and Gebhardt, 2018). This approach eliminates unnecessary variety in the product in the first step and includes modularization as the second step. The 
approach has been validated in a large number of industry and research projects and has reduced variety-induced complexity in companies, see e.g. (Greve and Krause, 2019).

\subsection{Variety-induced complexity caused by services}

One characteristic of service processes is that they are complex (Shostack, 1982; Benedettini and Neely, 2012). Their complexity does not only affect the company, but is usually also perceived by the customers (Thakor and Kumar, 2000; Reid, 2008). When considering complexity, it must be kept in mind that not all services generate the same degree of complexity. For example, pure maintenance or after-sales support usually mean a lower increase in complexity than performance-based services, which are billed on a usage basis. This is due to the fact that performance-based services usually consist of significantly more process steps and require more resources (Kreye et al., 2015). In general, the provision of services often leads to more complex contracts (Sundin and Bras, 2005).

According to Tuunanen and Cassab (2011), the effects of increased complexity are that the provision of services becomes more resource-intensive for the company. At the same time, it can also have a negative impact on customers, who can be overburdened by the high complexity and thus be deterred (Tuunanen and Cassab, 2011). This must be avoided, as in many cases customers are actively involved in the service processes (Vargo and Lusch, 2004).

Benedettini and Neely (2012) have dealt with service-related complexity. They analysed 76 potential factors from the literature that influence service complexity in the company. Of these 76 factors, some factors such as "service is offered according to many differentiated options", "service organization offers many different services", or "service contains a high number of sub-services" (Benedettini and Neely, 2012) can be attributed to a high variety of services, i.e. it is variety-induced complexity.

\subsection{Variety-induced complexity caused by PSS}

PSS is an interdisciplinary topic that is dealt with by the engineering and economic sciences, among others. It affects not only manufacturing companies, but also the service sector, such as finance or healthcare (Kreye et al., 2015). However, in most cases, PSS are created on the basis of existing products that are enriched with services (Tukker, 2004).

Similar to products, an increasing diversification and differentiation of the PSS gradually increases the variety of services and thus the internal complexity (Sundin et al., 2009; Zou et al., 2018; Larsen et al., 2019; Ezzat et al., 2019). Ezzat et al. (2019) have found that the complexity caused by product diversity is further increased by the coupling of tangible products and intangible services. Thus, a differentiation of the offer is usually connected with an increasing internal variety-induced complexity. The increasing complexity resulting from offering PSS poses a challenge for companies (Wang et al., 2011).

For this reason, research in the last few years has dealt with the topic of complexity from an engineering and economic point of view. Various drivers of variety-induced complexity have been identified. Figure 3 shows an excerpt of the various complexity drivers in the context of PSS.

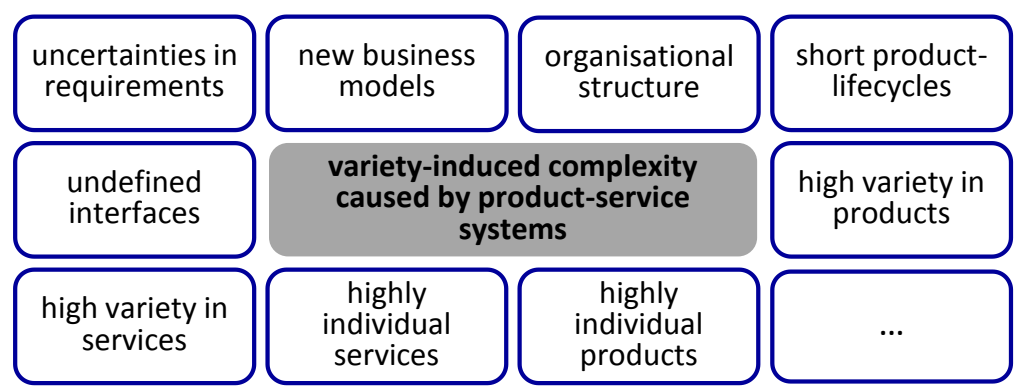

Figure 3. Drivers for variety-induced complexity (Zou et al., 2018; Tuunanen and Cassab, 2011; Benedettini and Neely, 2012)

In a literature analysis, Zou et al. (2018) analysed 23 publications from the field of PSS complexity to determine which reasons are cited for complexity in PSS. In addition to organizational and customerrelated reasons for increased complexity, various reasons are cited that can be directly or indirectly 
attributed to a high internal service diversity (Zou et al., 2018). Examples are the number of service components (Smith et al., 2014; Kreye et al., 2015; Braun and Hadwich, 2016; Sakao et al., 2017), the variety of service components (Braun and Hadwich, 2016; Brax and Visintin, 2017; Sakao et al., 2017) and the number of interactions between service components (Kreye et al., 2015; Sakao et al., 2017). These can be summarized as variety-induced complexity.

So far, services have often been seen only as an addition to the product, such as commissioning or product training. Thus, services are often not sufficiently taken into account in development or are even developed separately (Isaksson et al., 2009). At the same time, existing revenue sources such as maintenance and spare parts business are turning into a cost item for PSS. This paradigm shift must be taken into account when developing PSS and the associated business models (Manzini and Vezzoli, 2003; Tukker, 2015).

Since variety-induced complexity cannot be avoided and, according to Kreye et al. (2015), offering PSS leads to increasing complexity in the company, methods for the development of PSS must take this into account and try to reduce variety-induced complexity and make it controllable in the long term.

Tuunanen and Cassab (2011) assume that the approaches to develop modular product structures from product development (see e.g. Robertson and Ulrich, 1998; Du et al., 2001; Salvador, 2007) can also be applied to the development of PSS. For example, a service platform can be developed that provides the basic functionality and can be configured to different PSS variants using flexible service modules (Tuunanen and Cassab, 2011). Ezzat et al. (2019) also cite modularity as the key to mastering variety in the provision of PSS.

For these reasons, special methods must be provided for the development of PSS that take into account the entire product life cycle and the interaction between product and service (Mont, 2002; Isaksson et al., 2009; Lindahl et al., 2014; Tukker, 2015; Schuh et al., 2017). For PSS, it is no longer sufficient to develop individual products. The aim is the design of an entire system consisting of various components, processes and stakeholders (Isaksson et al., 2009).

A special feature of PSS development is the importance of the early phase of development. The full potential of PSS can only be exploited if product and services are developed together from the earliest concept phase (Isaksson et al., 2009; Martinez et al., 2010; Cavalieri and Pezzotta, 2012; Vasantha et al., 2012; Matschewsky et al., 2018). Vezzoli et al. (2015) and Alonso-Rasgado and Thompson (2006) emphasize the relevance of integrated product and service development in the early phase of product development in order to ensure efficient interaction of the individual product and service components during the entire product life cycle. Song and Sakao (2017) also see the early phase as critical for the success of PSS development. From this it can be derived that in development methods for PSS in particular the early phase of product development, e.g. concept development, must be taken into account in order to ensure the success of PSS. Isaksson et al. (2009) confirm this by writing in their contribution that new development processes are needed that already take into account the special features of PSS in the early phase of product development. In most cases, existing physical products must be adapted to the provision of PSS (Isaksson et al., 2009).

If these findings are combined with the proposed solution that the development of modular product structures is one way of reducing complexity (Tuunanen and Cassab, 2011; Ripperda and Krause, 2017; Ezzat et al., 2019), it can be concluded that in the development of modular PSS in particular variety-induced complexity should be reduced by consciously reducing service component and product component variety.

Various approaches for the development of modular PSS are known in the literature. In their contribution Larsen et al. (2018) analysed ten different methods for the development of modular PSS and derived four generic core steps from these, which can be found in almost all methods. These four steps are "identification of customer requirements", "translation of customer requirements into service specifications", "design of service modules" and the final "definition of the module structure" (Larsen et al., 2018). The methods analysed focus on modularisation of services, but modularization of products is not sufficiently addressed. In addition, only few methods contain all four steps. Methods are missed, which support the entire development. In addition, product and service are usually modularised separately (Larsen et al., 2018). This, and the simplification that only one service instead of a service family is considered, leads to the fact that the variety-induced complexity of the PSS cannot be sufficiently considered. 
Rennpferdt et al. (2019) confirm in a similar analysis that existing approaches for the development of modular PSS often only focus on the development of services and do not deal with the holistic development of product and service modules. In the approaches dealing with the development of modular product structures, modules are mainly formed from a technical-functional point of view. Product strategic module drivers are usually not taken into account. However, this is elementary with regard to the life cycle consideration of PSS and the long useful lives (Rennpferdt et al., 2019). Variety and variety-induced complexity are also not taken into account in the approaches analysed.

Finally, it can be said that variety-induced complexity occurs in products, services and PSS alike. One measure to reduce variety-induced complexity is the development of modular product structures that enable a reduction of internal diversity within the company. In order to develop modular PSS, new methods must be provided that are geared to the special requirements of PSS development. However, existing methods for developing modular PSS do not take into account the effects of variety and do not aim at reducing variety-induced complexity. In summary, there is still a need for research into a method for developing these modular PSS that considers the reduction of variety and thus the varietyinduced complexity as a separate step in the PSS development process. To fill this gap, a new framework is developed and presented in section 4.

\section{Proposed framework for the design of variety-oriented PSS}

In this section a framework for the development of variety-oriented modular PSS is presented. Its aim is to reduce variety and thus the variety-induced complexity. The framework covers the four core steps of PSS development according to Larsen et al. (2018) and is intended for companies that want to transfer existing products into PSS. Because this transition is time-consuming and resource-intensive, it is often executed in steps. Therefore, the main focus of the framework is on the development of product-oriented and use-oriented PSS instead of result-oriented PSS (compare Figure 2).

The novelty of the framework is the additional phase reduction of variety between the phases concept development and modularisation. This intermediate phase serves to reduce the variety before the modules are designed. This enables companies to specifically reduce the variety and the varietyinduced complexity during the development of PSS. In addition, a verification of the results is planned after each phase to ensure that the final PSS meets customer requirements. Figure 4 shows the general structure of the proposed framework. In the following, the basic ideas and goals of the framework are explained.

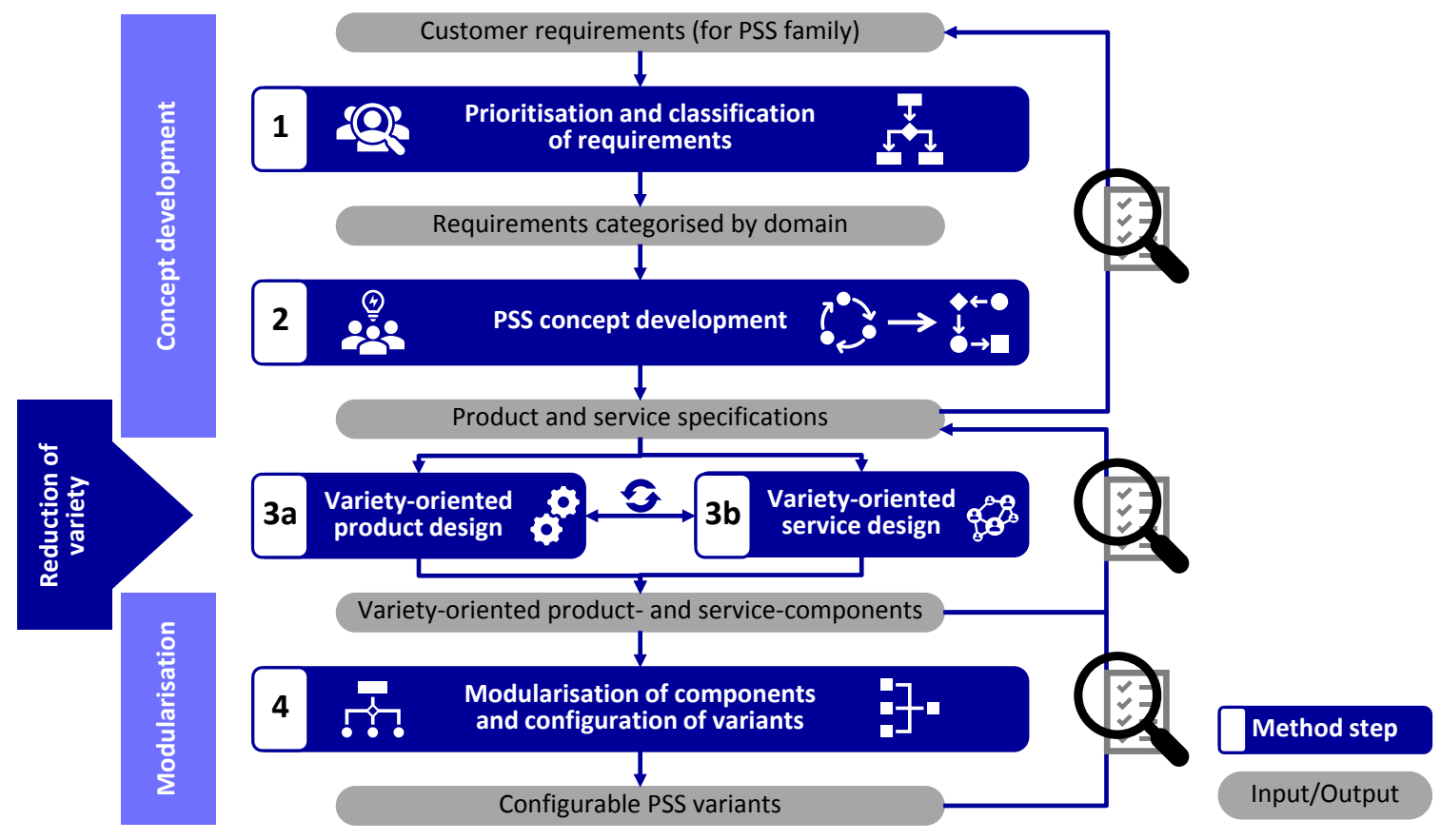

Figure 4. Proposed framework for the design of variety-oriented PSS 


\subsection{Prioritisation and classification of requirements}

In the first step, the customer requirements for the PSS are analysed. The goal is to categorise the requirements based on their affiliation to the product or service domain. The customer requirements are evaluated and grouped according to various criteria, such as costs, degree of novelty, effects on variety, etc. The criteria are selected specifically for each company and support the decision as to whether a customer requirement is to be realized in the product or service domain. A prioritisation of requirements helps to identify the most important requirements from the customer's point of view, as these must be considered with particular care in the subsequent concept phase.

The output of this step is the prioritised customer requirements, separated into requirements for the product and service domain, which form the input for the next step.

\subsection{PSS concept development}

The second step is the development of concepts for the PSS. The concept development is done in two sub-steps. First, a service concept is developed and the interfaces between service and product are defined. This is executed in several iterations, because first the most relevant requirements are implemented and then the less relevant requirements are included in the concept. Once the service concept has been created, supplementary product concepts are developed in the second sub-step to create a holistic PSS concept. Through the previously defined service concept and the interfaces the dependencies between product and service can be considered and simplified for the overall concept. This sequential concept development reduces the danger that there are different solutions for the same requirement in the PSS concept, which would increase the variety-induced complexity.

With the help of the described procedure, different PSS concept alternatives can be developed, each pursuing different objectives, e.g. low service share or low manufacturing costs. The concepts created in this way are then evaluated and a final concept is selected for further processing.

The output of this step is a concept for the PSS with the associated functions, as well as the product and service specifications that needs to be transferred into product and service components.

\subsection{Design of variety-oriented products and services}

In the third step, the selected concept is realized in product and service components required for the PSS variants. The development of products and services is carried out in parallel processes by the respective experts who have the appropriate specialist knowledge. The parallel development of the variety-oriented components enables the product and service domains to be decoupled as far as possible. This reduces the dependencies between products and services and also the complexity of the PSS. Nevertheless, continuous coordination and alignment of the two parallel development processes is essential for parallel development. In particular, the interfaces between the domains must be coordinated and verified.

For the product domain, the Design for Variety method unit according to the Integrated PKT-approach (Krause et al., 2014) is used, since this method unit reduces the product variety. Since electronic components and software are also considered in PSS, adaptations of the method to the special boundary conditions are necessary (Rennpferdt and Krause, 2019). An additional input for varietyoriented product design is the existing product structure of the company. This could be used as a starting point in the design of the product components.

For the development of the service components the extended service blueprinting according to Hara et al. (2009) could be adapted and used to reduce the service variety. For this the design principles of the Design for Variety method can be used (Krause et al., 2014). Depending on what is available in the company, existing service concepts can be used as input or new services can be developed.

The results of this step are variety-oriented product and service components. These realise the required components of the PSS with as little internal variety as necessary and enable a reduction of varietyinduced complexity.

\subsection{Modularisation of components and configuration of variants}

In the fourth step of the framework the Life Phase Modularisation from the Integrated PKT-approach (Krause et al., 2014) is used to develop PSS modules. The Life Phase Modularisation combines 
technical-functional with product-strategic aspects to define the modules (Krause et al., 2014). Thus, the modules can be designed in such a way that the requirements for the module structure of the different life phases can be taken into account. In order to take services into account, it is necessary to add service-specific module drivers. Another necessary adaption is the consideration of the usage phase in the harmonisation of the module structure.

From the developed modules, the final PSS can then be configured and offered on the market. Due to the variety-oriented development these PSS cause as little variety-induced complexity as possible within the company and thus improve the competitive position on the market.

The output of this step is a module structure for the PSS family.

\section{Conclusion and outlook}

In this contribution, definitions of product, service and PSS are given. This is followed by an explanation, based on a literature review, how complexity in general and variety-induced complexity in particular arises in products, services and PSS and what effects on companies they may have. As a countermeasure against increasing complexity, the development of modular product structures is discussed in the literature. To develop modular product structures in PSS, existing methods need to be adapted. Since existing methods for the design of modular PSS do not take variety-induced complexity into account, a need for a method for the development of variety-oriented PSS is identified. Subsequently, a framework is presented which is supposed to cover this need. The four-step framework is briefly introduced, and the basic ideas and the related method steps are explained. The novelty is an additional design phase between the concept development and the modularisation in which the product and service components are designed to cause as little variety as possible. The proposed framework is designed to support companies to diversify their product range (meaning products and services) while keeping variety-induced complexity as low as possible and thus remain more competitive.

In future, the framework needs to be elaborated. Among other things, tools and support for the individual steps are to be provided. Also, it should be elaborated which method steps are best suited for the aims of the four steps. In addition, further criteria and company constraints should be taken into account when evaluating the classification into product or service specifications. Finally, the framework must be validated using an industrial example.

\section{References}

Alonso-Rasgado, T. and Thompson, G. (2006), "A rapid design process for Total Care Product creation", Journal of Engineering Design, Vol. 17 No. 6, pp. 509-531. http://doi.org/10.1080/09544820600750579

Baines, T.S. et al. (2007), "State-of-the-art in product-service systems", Proceedings of the Institution of Mechanical Engineers, Part B: Journal of Engineering Manufacture, Vol. 221 No. 10, pp. 1543-1552. http://doi.org/10.1243/09544054JEM858

Benedettini, O. and Neely, A. (2012), "Complexity in services: an interpretative framework", paper presented at 23rd Annual Conference of the Production and Operations Management Society, Chicago, Illinois, U.S.A.

Braun, C. and Hadwich, K. (2016), "Complexity of internal services: Scale development and validation", Journal of Business Research, Vol. 69 No. 9, pp. 3508-3522. http://doi.org/10.1016/j.jbusres.2016.01.035

Brax, S.A. and Visintin, F. (2017), "Meta-model of servitization: The integrative profiling approach", Industrial Marketing Management, Vol. 60, pp. 17-32. http://doi.org/10.1016/j.indmarman.2016.04.014

Brosch, M. and Krause, D. (2011), "Complexity from the Perspective of the Design for Supply Chain Requirements", paper presented at 2nd Conference on the Interdependencies between New Product Development and Supply Chain Management, Milano.

Cavalieri, S. and Pezzotta, G. (2012), "Product-Service Systems Engineering: State of the art and research challenges", Computers in Industry, Vol. 63 No. 4, pp. 278-288. http://doi.org/10.1016/j.compind.2012.02.006

Du, X., Jiao, J. and Tseng, M.M. (2001), "Architecture of Product Family: Fundamentals and Methodology", Concurrent Engineering, Vol. 9 No. 4, pp. 309-325. http://doi.org/10.1177/1063293X0100900407

ElMaraghy, H. et al. (2013), "Product variety management", CIRP Annals, Vol. 62 No. 2, pp. 629-652. http://doi.org/10.1016/j.cirp.2013.05.007

ElMaraghy, W. et al. (2012), "Complexity in engineering design and manufacturing”, CIRP Annals, Vol. 61 No. 2, pp. 793-814. http://doi.org/10.1016/j.cirp.2012.05.001 
Ezzat, O. et al. (2019), "Product and service modularization for variety management", Procedia Manufacturing, Vol. 28, pp. 148-153. http://doi.org/10.1016/j.promfg.2018.12.024

Goedkoop, M. (1999), Product Service systems, Ecological and Economic Basics.

Goldstein, S.M. et al. (2002), “The service concept: the missing link in service design research?", Journal of Operations Management, Vol. 20 No. 2, pp. 121-134. http://doi.org/10.1016/S0272-6963(01)00090-0

Greve, E. and Krause, D. (2019), "Long-term effects of modular product architectures: An empirical follow-up study”, Procedia CIRP, Vol. 84, pp. 731-736. http://doi.org/10.1016/j.procir.2019.04.274

Hara, T. et al. (2009), "Service CAD system to integrate product and human activity for total value", $C I R P$ Journal of Manufacturing Science and Technology, Vol. 1 No. 4, pp. 262-271. http://doi.org/10.1016/ j.cirpj.2009.06.002

Isaksson, O., Larsson, T.C. and Rönnbäck, AÖ (2009), "Development of product-service systems: challenges and opportunities for the manufacturing firm", Journal of Engineering Design, Vol. 20 No. 4, pp. 329-348. http://doi.org/10.1080/09544820903152663

Krause, D. et al. (2014), "Integrated Development of Modular Product Families: A Methods Toolkit”, In: Simpson, T.W., Jiao, J., Siddique, Z. and Hölttä-Otto, K. (Eds.), Advances in Product Family and Product Platform Design, Springer New York, New York, NY, pp. 245-269. http://doi.org/10.1007/978-1-4614-7937-6_10

Krause, D. and Gebhardt, N. (2018), Methodische Entwicklung Modularer Produktfamilien: Hohe Produktvielfalt Beherrschbar Entwickeln, Vieweg, Berlin, Heidelberg. http://doi.org/10.1007/978-3-662-53040-5

Kreye, M.E., Roehrich, J.K. and Lewis, M.A. (2015), "Servitising manufacturers: the impact of service complexity and contractual and relational capabilities", Production Planning \& Control, Vol. 26 No. 14-15, pp. 1233-1246. http://doi.org/10.1080/09537287.2015.1033489

Larsen, M.S.S. et al. (2018), "Modularity in Product-Service Systems: Literature Review and Future Research Directions", In: Moon, I., Lee, G.M., Park, J., Kiritsis, D. and Cieminski, G. von. (Eds.), Advances in Production Management Systems. Production Management for Data-Driven, Intelligent, Collaborative, and Sustainable Manufacturing, IFIP Advances in Information and Communication Technology, Vol. 535, Springer International Publishing, Cham, pp. 150-158. http://doi.org/10.1007/978-3-319-99704-9_19

Larsen, M.S.S. et al. (2019), "Challenges in developing modular services in manufacturing companies: A multiple case study in Danish manufacturing industry", Procedia CIRP, Vol. 81, pp. 399-404. http://doi.org/10.1016/j.procir.2019.03.069

Lindahl, M., Sundin, E. and Sakao, T. (2014), "Environmental and economic benefits of Integrated Product Service Offerings quantified with real business cases", Journal of Cleaner Production, Vol. 64, pp. 288296. http://doi.org/10.1016/j.jclepro.2013.07.047

Manzini, E. and Vezzoli, C. (2003), "A strategic design approach to develop sustainable product service systems: examples taken from the 'environmentally friendly innovation' Italian prize", Journal of Cleaner Production, Vol. 11 No. 8, pp. 851-857. http://doi.org/10.1016/S0959-6526(02)00153-1

Martinez, V. et al. (2010), "Challenges in transforming manufacturing organisations into product-service providers", Journal of Manufacturing Technology Management, Vol. 21 No. 4, pp. 449-469. http://doi.org/ 10.1108/17410381011046571

Matschewsky, J., Kambanou, M.L. and Sakao, T. (2018), "Designing and providing integrated product-service systems - challenges, opportunities and solutions resulting from prescriptive approaches in two industrial companies", International Journal of Production Research, Vol. 56 No. 6, pp. 2150-2168. http://doi.org/ 10.1080/00207543.2017.1332792

Meier, H., Roy, R. and Seliger, G. (2010), “Industrial Product-Service Systems-IPS 2", CIRP Annals, Vol. 59 No. 2, pp. 607-627. -http://doi.org/10.1016/j.cirp.2010.05.004

Mont, O.K. (2002), "Clarifying the concept of product-service system", Journal of Cleaner Production, Vol. 10 No. 3, pp. 237-245. http://doi.org/10.1016/S0959-6526(01)00039-7

Rathnow, P.J. (1993), Integriertes Variantenmanagement: Bestimmung, Realisierung und Sicherung der optimalen Produktvielfalt, Innovative Unternehmensführung, Vandenhoeck \& Ruprecht, Göttingen.

Reid, M. (2008), "Contemporary marketing in professional services", Journal of Services Marketing, Vol. 22 No. 5, pp. 374-384. http://doi.org/10.1108/08876040810889148

Rennpferdt, C., Greve, E. and Krause, D. (2019), "The Impact of Modular Product Architectures in PSS Design: A systematic Literature Review”, Procedia CIRP, Vol. 84, pp. 290-295. http://doi.org/10.1016/j.procir. 2019.04.197

Rennpferdt, C. and Krause, D. (2019), “Adapted Design for Variety: Consideration of the Software-Domain”, Proceedings 2019 IEEE International Conference on Industrial Engineering and Engineering Management (IEEM 2019), pp. 950-954. http://doi.org/10.1109/IEEM44572.2019.8978493

Ripperda, S. and Krause, D. (2017), "Cost Effects of Modular Product Family Structures: Methods and Quantification of Impacts to Support Decision Making”, Journal of Mechanical Design, Vol. 139 No. 2, pp. 219. http://doi.org/10.1115/1.4035430 
Robertson, D. and Ulrich, K. (1998), "Planning for Product Platforms”, Sloan Management Review, Vol. 39 No. 4, pp. 19.

Roy, R. et al. (2011), "Addressing the impact of high levels of product variety on complexity in design and manufacture", Proceedings of the Institution of Mechanical Engineers, Part B: Journal of Engineering Manufacture, Vol. 225 No. 10, pp. 1939-1950. http://doi.org/10.1177/0954405411407670

Sakao, T., Song, W. and Matschewsky, J. (2017), "Creating service modules for customising product/service systems by extending DSM”, CIRP Annals, Vol. 66 No. 1, pp. 21-24. http://doi.org/10.1016/j.cirp.2017.04.107

Salvador, F. (2007), "Toward a Product System Modularity Construct. Literature Review and Reconceptualization”, IEEE Transactions on Engineering Management, Vol. 54 No. 2, pp. 219-240. http://doi.org/10.1109/TEM.2007.893996

Schuh, G. et al. (2017), "Evaluation of Variety-induced Costs in Product-Service Systems (PSS)", Procedia CIRP, Vol. 61, pp. 673-678. http://doi.org/10.1016/j.procir.2016.11.239

Shostack, G.L. (1982), "How to Design a Service”, European Journal of Marketing, Vol. 16 No. 1, pp. 49-63. http://doi.org/10.1108/EUM0000000004799

Smith, L., Maull, R. and C.L. Ng, I. (2014), "Servitization and operations management: a service dominant-logic approach", International Journal of Operations \& Production Management, Vol. 34 No. 2, pp. 242-269. http://doi.org/10.1108/IJOPM-02-2011-0053.

Song, W. and Sakao, T. (2017), “A customization-oriented framework for design of sustainable product/service system”, Journal of Cleaner Production, Vol. 140, pp. 1672-1685. http://doi.org/10.1016/j.jclepro.2016.09.111

Sundin, E. and Bras, B. (2005), "Making functional sales environmentally and economically beneficial through product remanufacturing", Journal of Cleaner Production, Vol. 13 No. 9, pp. 913-925. http://doi.org/10. 1016/j.jclepro.2004.04.006

Sundin, E. et al. (2009), “Achieving mass customisation through servicification”, International Journal of Internet Manufacturing and Services, Vol. 2 No. 1, pp. 56. http://doi.org/10.1504/IJIMS.2009.031340

Thakor, M.V. and Kumar, A. (2000), "What is a professional service? A conceptual review and bi-national investigation", Journal of Services Marketing, Vol. 14 No. 1, pp. 63-82. http://doi.org/10.1108/ 08876040010309211

Tukker, A. (2004), "Eight types of product-service system: eight ways to sustainability? Experiences from SusProNet", Business Strategy and the Environment, Vol. 13 No. 4, pp. 246-260. http://doi.org/10.1002/ bse. 414

Tukker, A. (2015), "Product services for a resource-efficient and circular economy - a review", Journal of Cleaner Production, Vol. 97, pp. 76-91. http://doi.org/10.1016/j.jclepro.2013.11.049

Tukker, A. and Tischner, U. (2006), "Product-services as a research field: past, present and future. Reflections from a decade of research", Journal of Cleaner Production, Vol. 14 No. 17, pp. 1552-1556. http://doi.org/ 10.1016/j.jclepro.2006.01.022

Tuunanen, T. and Cassab, H. (2011), "Service Process Modularization”, Journal of Service Research, Vol. 14 No. 3, pp. 340-354. http://doi.org/10.1177/1094670511413912

Vargo, S.L. and Lusch, R.F. (2004), "Evolving to a New Dominant Logic for Marketing”, Journal of Marketing, Vol. 68 No. 1, pp. 1-17. http://doi.org/10.1509/jmkg.68.1.1.24036

Vasantha, G.V.A. et al. (2012), "A review of product-service systems design methodologies", Journal of Engineering Design, Vol. 23 No. 9, pp. 635-659. http://doi.org/10.1080/09544828.2011.639712

Vezzoli, C. et al. (2015), "New design challenges to widely implement 'Sustainable Product-Service Systems"”, Journal of Cleaner Production, Vol. 97, pp. 1-12. http://doi.org/10.1016/j.jclepro.2015.02.061

Wang, P.P. et al. (2011), "Modular Development of Product Service Systems”, Concurrent Engineering, Vol. 19 No. 1, pp. 85-96. http://doi.org/10.1177/1063293X11403508

Zou, W., Brax, S.A. and Rajala, R. (2018), "Complexity in Product-Service Systems: Review and Framework", Procedia CIRP, Vol. 73, pp. 3-8. http://doi.org/10.1016/j.procir.2018.03.319 